\title{
Bridging the gap
}

\author{
Elizabeth Kay \\ Editor, EBD
}

It is with a sense of enormous pride, and recognition of how very fortunate I am, that I write this, my first Editorial as Editor of $E B D$. Hopefully it will be the first of many over the years to come. My name is Professor Elizabeth Kay and I absolutely relish the opportunity I have been given through my appointment as the new Editor. The very first thing I want to do is to pay homage to my predecessor, and the previous Editor of $E B D$, Professor Derek Richards.

Derek has not only edited the Journal, but also led the cause of evidence-based dentistry over the past 20 years. His contribution to the advancement of rational policy and research based practice in dentistry, via the careful analysis of evidence, has been huge. We all, not least myself, owe Derek great gratitude for all he has done to advance the cause of science holding sway over dogma. On behalf of everyone who has benefitted from, developed their thinking because of, and expanded their practice as a result of your great work, thank you, Derek.

So I have very big shoes to fill in the role of Editor. And while I cannot hope to achieve what Derek has achieved, or make the same contribution as he has, I would like to take this opportunity to explain my reasons and motivations for wishing to take up the Editors 'baton'.

I am enormously proud of my profession. Although I have followed an academic career, I am , and feel like, first and foremost, a dentist. Equally, while I am a specialist and consultant in Dental Public Health, I have, for my entire working life continued to practice clinically. I have done so because I like being a dentist. I like being a real, live, wet-fingered dentist. And I like it because I am immensely proud of it. I have the great joy, as do all of you reading this, of belonging to a professional group who do things no other group does, and which is like no other professional body of people. If you think about it, there really is no other working arena which requires a set of skills so eclectic and so demanding. There are

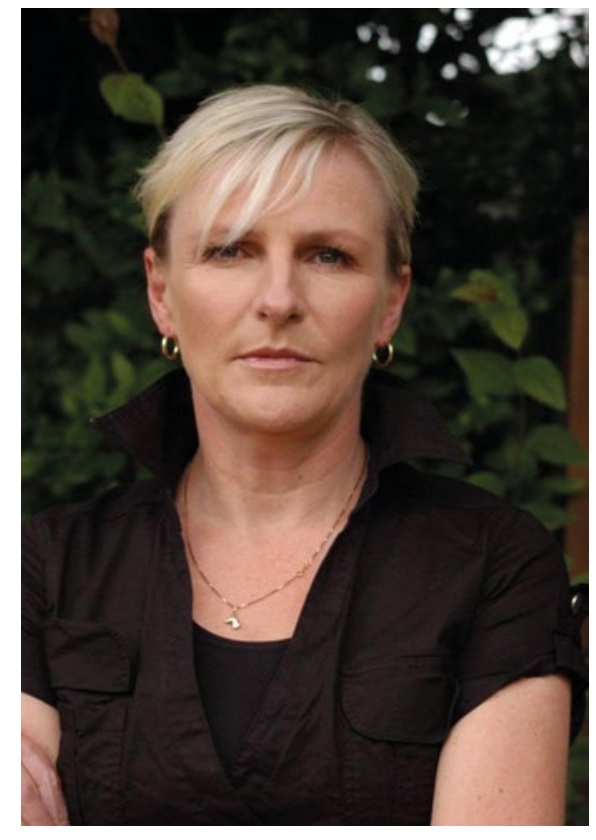

Elizabeth Kay

no other professions which depend on, and require, a deeply intellectual approach and profound knowledge, which in turn must be combined with practical artistry, as in dentistry. I celebrate that, and intend to lead this journal to both expose and promulgate the evidence we need to have at our finger tips in order to have both the scientific skill and deep understanding of people and aesthetics that we need each day in our surgeries.

Dentistry is about so many things. Technical skill, of course is a requirement, but unlike other professions our surgical expertise works within tolerances of micrometres. Not millimetres or, centimetres, but micrometres! And as if that weren't enough, we utilise these skills while working in a very tiny dark wet cave... (aka a mouth!). And while we are doing so, we deal with the emotions, neuroses, vanities and social mores which people connect with their mouths and teeth. Finally, while doing all these things we have to remain happy, calm, supportive whilst planning, managing, and conducting a business. There simply is no other professional world which can say that it contains people with skills that deep, difficult and diverse. And that is the focus I want to bring to $E B D$. This journal is for practitioners, clinicians and those working at the front line. It exists, in my view, in order to interpret and 'distil' important research evidence so that it can be used in ordinary, everyday dental practice. Thus, my central aim will be to bridge the gap between the world of research and 'real-world' dentistry. I will aim to make research truly meaningful to those who actually deliver dental care to the population. If I can make the smallest contribution to enhancing meaningful two-way communication between academic dentistry and dentistry in practice I will have done what I am setting out to do.

I propose to try to achieve this ambition by, firstly, trying to ensure that the summarised evidence we present in $E B D$ relates to all aspects of clinical practice. I want to expand our brief beyond evidence about techniques, pharmacology, and materials, and review research about patient psychology, healthcare management, health economics, and occupational health. We will cover any evidence that is directly relevant and of interest to those carrying out clinical practice.

I also hope to develop ways of alerting dental practice to the existence of new and exciting research evidence to try to speed up the current shocking time lag between proof of benefit and uptake in practice. Hopefully we will involve both sister publications and social media in this bid to publicise helpful innovations. This projection of the importance and relevance of $E B D$ 's content to practitioners and policy makers, as well as researchers, is my second key aim. And if, through this, we manage to excite one extra person who is focussed on clinical practice about the relevance of research to their working lives, I will consider it a job well done.

I hope you will support and approve of this proposed direction for travel for $E B D$... but for now...just wish me luck!

Evidence-Based Dentistry (2019) 20, 36. doi:10.1038/sj.ebd.6401125 